\title{
LA FORMA ES FONDO: CÓMO SE NOMBRAN Y DECIDEN LOS MINISTROS DE LA SUPREMA CORTE DE JUSTICIA
}

\author{
FORM IS CONTENT: HOW ARE JUSTICES APPOINTED AND HOW \\ DO THEY DECIDE IN THE SUPREME COURT OF JUSTICE
}

\section{Carlos ElizOndo MAYER-SERRA \\ Ana Laura MAGALONI}

RESUMEN: Las encuestas muestren una baja confianza en la Suprema Corte de Justicia. Este trabajo pone atención en algunas cuestiones formales que impactan en el desempeño y legitimidad del máximo tribunal. El punto de partida del análisis es que la forma importa. Por un lado, las reglas de elección y duración del cargo tienen un efecto sobre quienes llegan a ministros y con qué expectativas. Por el otro, el método por el cual los once ministros llegan a su decisión afecta el fondo de las sentencias. El ensayo se divide en tres secciones: la primea estudia qué dicen los datos respecto a la confianza de los ciudadanos en la Suprema Corte. La segunda analiza cómo la forma de elegir a los ministros afecta en quienes llegan a serlo y con qué objetivos profesionales. Finalmente, en la tercera se estudia cómo los aspectos formales del proceso de decisión del Pleno de la Suprema Corte afectan las sentencias, tanto formal como sustantivamente $\mathrm{y}$, por ende, la legitimidad del tribunal.

Palabras clave: derecho constitucional; derecho comparado; política comparada; justicia procedimental; reglas de decisión.
ABSTRACT: Opinion polls show low confidence in the Supreme Court. This article brings attention to some formal issues that impact eh performance and legitimacy of our Court. The starting point of this analysis is that formal questions matter. On one hand, the rules of election and the time in office affect who takes a seat in the Court and with what expectations. On the other hand, the procedure by which the eleven justices reach a decision affects the contents of their ruling. This work is divided into three sections: the first considers what the data from the opinion polls say about confidence in the Supreme Court. The second will consider how the way in which Justices are elected affects who makes it to the Court as Justice and with what kind of professional goals. Finally, we will study how formal aspects of the decision-making process of the Supreme Court affect its ruling, both formal and substantively, and, therefore, the legitimacy of the Court as a whole.

Descriptors: Constitutional Law; Comparative Law; Comparative Politics; Procedural Justice; Rules of Decision. 


\section{INTRODUCCIÓN ${ }^{1}$}

Los datos muestran que la Suprema Corte no ha logrado alcanzar niveles constantes y amplios de confianza por parte de la ciudadanía. Como se verá en este trabajo, la percepción social respecto al quehacer de la Corte tiene dos características: 1) cambia mucho a través del tiempo, y 2) a partir de julio del 2007, el porcentaje de personas que tienen "mucha" confianza en la Corte ha sido mucho más bajo de quienes afirman tener poca o nada de confianza. ¿Qué es lo que explica esta falta de confianza en el máximo tribunal del país? ¿Qué tendrían que hacer los ministros para impactar positivamente en esta percepción ciudadana?

Las respuestas a estas interrogantes son extraordinariamente complejas. La literatura académica en la materia, por lo menos la que se ha producido desde el ámbito del derecho, indica que los tribunales constitucionales que han alcanzado los mayores niveles de legitimidad han sido los que han logrado acertar en la definición de su papel en el delicado equilibrio de poderes de un régimen democrático. Según Marian Ahumada, la jurisdicción constitucional, tanto en Europa como en Estados Unidos, logró afianzar su legitimidad cuando "su potencial se puso al servicio de la defensa de los intereses sociales que no lograban representación en las asambleas, que quedaban sistemáticamente al margen de la agenda política". ${ }^{2}$ Es decir, se requiere una jurisdicción constitucional entendida como aliada de los grupos vulnerables y de la defensa de una sociedad verdaderamente pluralista y tolerante. El control constitucional en Europa y Estados Unidos, desde mediados del siglo pasado hasta la década de los ochenta, se concibió como un instrumento básico para la construcción de un piso común de derechos propios del estatus jurídico del ciudadano. Los tribunales constitucionales que lograron desempeñar exitosamente esta tarea adquirieron, en palabras de Ahumada, "una popularidad hasta entonces desconocida". 3

La Suprema Corte mexicana se ha quedado lejos de desempeñar este papel. Su diseño no estuvo pensado para ese objetivo, ni tampoco los mi-

1 Una versión más corta de este documento apareció bajo el título "Cómo decide la Corte", Nexos, vol. XXX, núm. 369, septiembre de 2008.

2 La jurisdicción constitucional en Europa. Bases teóricas y políticas, España, Thomson-Cívitas, 2007, p. 31.

3 Idem.... 
nistros han sabido utilizar estratégicamente su facultad de atracción para definir una agenda jurisdiccional que les permita construir una alianza con la ciudadanía. ${ }^{4}$ Es decir, una posible hipótesis de por qué la Corte no alcanza a afianzar su legitimidad tiene que ver con que, a fin de cuentas, no ha logrado definir correctamente su papel en el proceso de consolidación de la democracia mexicana. ${ }^{5}$ Es un tribunal que ha puesto demasiada atención a los conflictos políticos y a los litigios de la élite y ha relegado a un segundo plano los asuntos que de verdad importan a la mayoría de los ciudadanos.

Sin embargo, este trabajo no pretende analizar desde esta perspectiva el problema de la débil legitimidad de nuestro tribunal constitucional. Su objetivo es más modesto: poner atención a algunas cuestiones formales que impactan en el desempeño y legitimidad de nuestra Suprema Corte. Existen dos que nos parecen centrales: el mecanismo de selección de Ministros y el proceso a través del cual el Pleno de la Corte llega a su veredicto.

El punto de partida del análisis es que la forma importa. Por un lado, las reglas de elección y duración de encargo tienen un efecto sobre quienes llegan a ministros y con qué expectativas. Por el otro, el método por el cual los once ministros llegan a su decisión, cualquiera que éste sea, afecta lo que se decide.

4 Magaloni, Ana Laura, ¿Por qué la Suprema Corte no ha sido un instrumento para la defensa de derechos fundamentales?”, en Ferrer Mac-Gregor, Edyardi y Zaldívar, Arturo (coords.), Ciencia del derecho procesal constitucional. Estudios en homenaje a Héctor Fix-Zamudio, México, Instituto de Investigaciones Jurídicas, 2008, pp. 271 y ss.

5 Sin duda, uno de los problemas centrales de nuestra Suprema Corte tiene que ver con la calidad argumentativa de sus decisiones. Cómo se logran sentencias jurídicamente sólidas y argumentadas con contundencia es un tema que queda fuera del alcance de este texto. Sin embargo, cabe señalar que en los países donde el poder judicial ha desarrollado una lógica argumentativa más compacta y clara, le es mucho más fácil comunicarla e influir a través de sus sentencias y por tanto legitimar su actuación. El fondo del problema es la forma en la que los jueces conciben su papel y entiende el papel del derecho. Es decir, el derecho es un sistema de normas dado y la función de juez es simplemente aplicarlo al caso concreto, o bien, el derecho es un instrumento al servicio de la sociedad que permite pacificar conflictos, a través de los tribunales, de forma efectiva. En este segundo caso, los jueces tienen que asumir explícitamente que la aplicación de la ley no es una simple operación aritmética, sino un proceso para alcanzar dentro de la legalidad una sociedad con menos conflictos abiertos. 
Este trabajo se divide en tres secciones: la primera estudia qué dicen los datos respecto la confianza en la Suprema Corte y cómo se ha movido ésta a lo largo del tiempo. La segunda analiza cómo la forma de elegir Ministros afecta a quienes llegan a ser ministros y con qué objetivos profesionales. Finalmente, en la tercera sección, se estudia cómo los aspectos formales del proceso de decisión del Pleno de la Suprema Corte afectan las sentencias, tanto formal como sustantivamente, y por ende su legitimidad. Al final se plantean las conclusiones de este trabajo.

\section{CONFIANZA CIUDADANA EN LA SuPREMA CORTE DE JUSTICIA}

Nuestra Corte Suprema es ya el árbitro último de muchos de los conflictos importantes entre poderes, como entre ciudadanos y autoridad. Sólo en el año 2009, como señaló el ministro Ortiz Mayagoita al inicio del primer periodo de sesiones, el Pleno tenía en puerta una gran cantidad de asuntos que iban desde controversias constitucionales importantes, como la despenalización del aborto, amparos en materia fiscal y financiera, y la investigación sobre el caso Oaxaca. ${ }^{6}$

Asimismo, la visibilidad mediática de la Corte ha ido en aumento de forma permanente. Sus sentencias son cada vez más seguidas por los medios de comunicación. Sin embargo, como institución, no ha logrado alcanzar los niveles de credibilidad deseable en un órgano de esta naturaleza, como se observa en las siguientes gráficas.

6 Véase el discurso en http://www.scjn.gob.mx/SiteCollectionDocuments/PortalSCJN/ MediosPub/DiscursosyConferenciasPresidenteSCJN/ENE\%2002\%202009_GOM\%20 APERTURA\%2010\%20PERIODO\%20SESIONES.pdf 
Dígame por favor, ¿qué opinión tiene usted de...?

La Suprema Corte de Justicia de la Nación

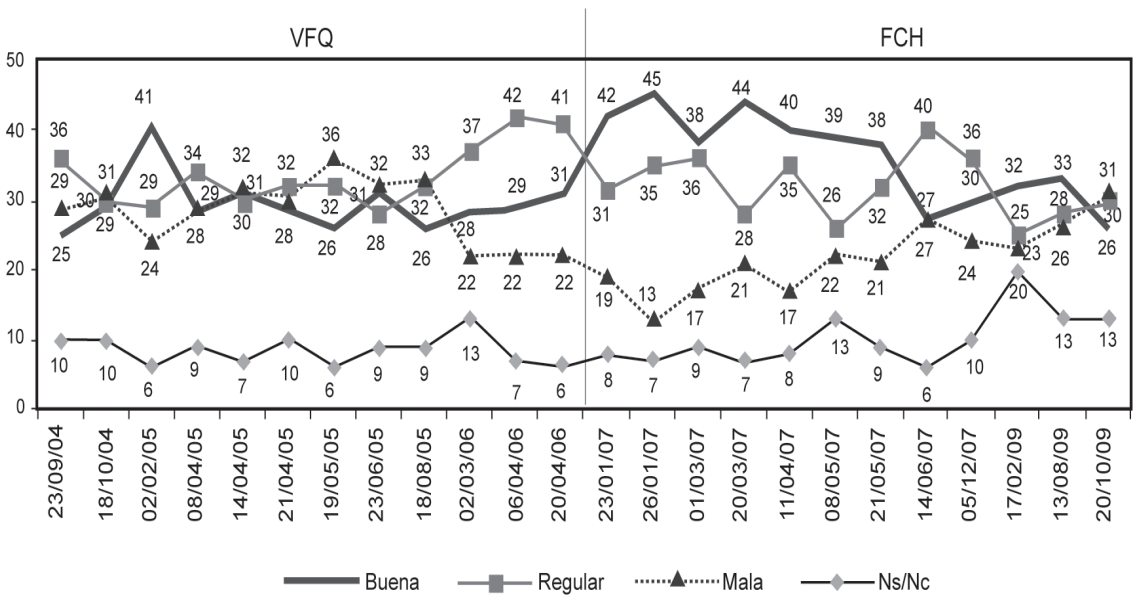

Fuente: Beltrán y Asociados, Acontecer Nacional y Opinión Pública, vol. IX, núm. 40, 26 de octubre de 2009.

Esta serie de tiempo, como se puede observar, mide la opinión que tienen los ciudadanos de la Suprema Corte mes a mes, desde septiembre de 2004 hasta octubre de 2009. Lo primero que se puede observar es que la opinión ciudadana cambia con frecuencia. En un mes la opinión favorable puede ser $41 \%$ (febrero, 2005) y al siguiente mes dicha opinión pasa a $28 \%$. También se puede observar que, desde agosto de 2005 hasta la fecha, el porcentaje de personas que tiene una opinión negativa de la Corte ha sido menor en forma constante que el porcentaje de una opinión regular o buena. Sin embargo, con todo, los ciudadanos no tienen una posición completamente definida y estable respecto a la Suprema Corte.

La siguiente tabla muestra la serie de tiempo con respecto a la confianza en la Suprema Corte, ya no sólo la opinión como lo hacía la anterior. Esta serie es más corta, pues sólo abarca de enero de 2006 a octubre de 2009, pero da cuenta de sentencias particularmente visibles. 


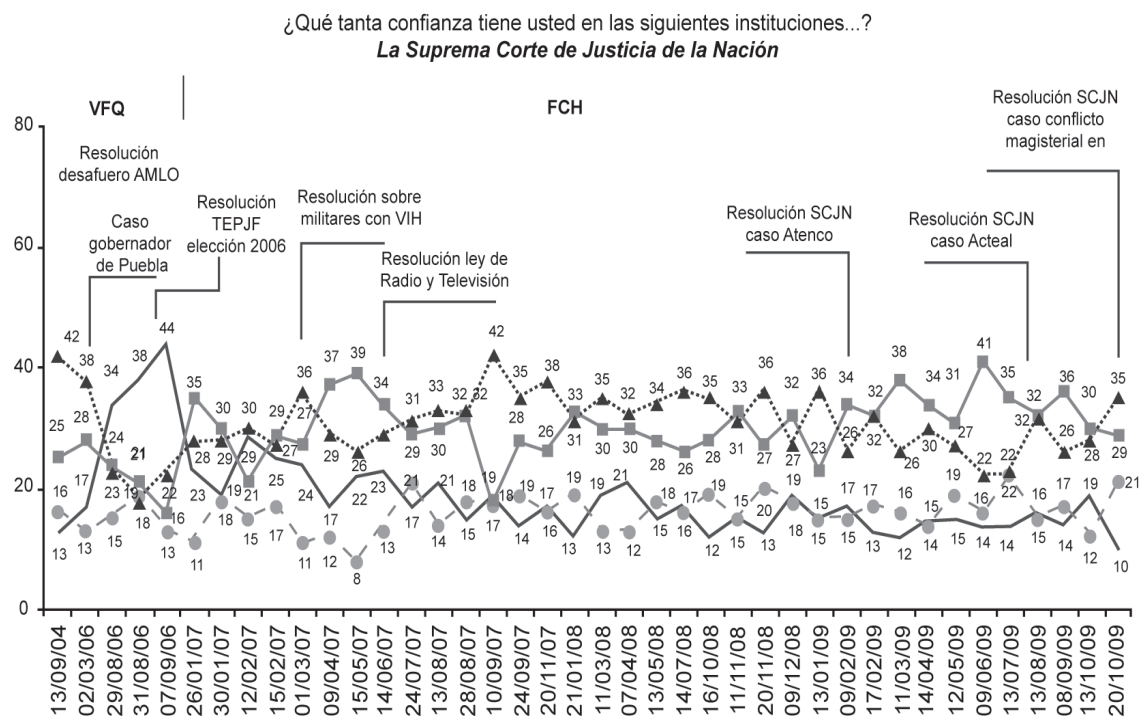

Sumando "Ns/Nc"= $100 \%$

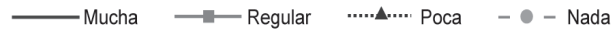

Fuente: Beltrán y Asociados, Acontecer Nacional y Opinión Pública, vol. IX, núm. 40, 26 de octubre de 2009.

Es interesante observar que el punto máximo de confianza de la Corte fue en agosto de 2006, fecha en la que alcanza una confianza de $44 \%$. Lo interesante es que es precisamente en ese mes cuando el Tribunal Electoral del Poder Judicial Federal emite su resolución con respecto a la validez de la elección presidencial de ese año. Es decir, posiblemente ese nivel de confianza no haya tenido nada que ver con lo que la Corte hizo o dejó de hacer en ese tiempo.

Lo más interesante de esta serie de tiempo es que, como se puede apreciar, "mucha" confianza en la Corte es sistemáticamente la opción menos frecuente. Es decir, a diferencia de lo que ocurre con la gráfica anterior en donde la opinión "mala" de la Corte es la opción menos frecuente, tratándose de los niveles de confianza sucede a la inversa: la mayoría de la población tiene "regular" o "poca" confianza en la Corte y un porcentaje mucho menor sostiene tener "mucha" confianza. Ello nos indica que no es lo mismo medir opinión sobre la Corte que niveles de confianza. Sin 
duda el concepto de confianza abarca algo más que la sola percepción sobre la imagen del máximo tribunal.

Al mismo tiempo, es interesante observar que las resoluciones de la Corte en los casos que han tenido más cobertura mediática no parecen impactar de forma significativa los niveles de confianza. Habría que hacer estudios de mayor profundidad respecto a esta cuestión; sin embargo, es posible que las estimaciones de la prensa y la opinión pública —que son resoluciones de alto impacto- no tengan que ver con lo que los ciudadanos comunes y corrientes estiman que son sus problemas fundamentales y las injusticias que perciben o padecen. Además, una de sus facultades más visibles, la de investigar un asunto particularmente delicado, como el de los presuntos excesos del gobierno frente a la APPO en el 2006 — contemplado así en la Constitución-, termina en un mero posicionamiento de la Corte, no a acciones que validen sus conclusiones. De cualquier forma, lo que sí es posible concluir es que la Corte no logra afianzar su legitimidad en la sociedad.

Eso es así, a pesar de que es un órgano que cuesta grandes cantidades de dinero y que tiene un presupuesto elevado para difundir su actuar, como lo muestran los siguientes cuadros.

\begin{tabular}{|l|c|}
\hline \multicolumn{2}{|c|}{ Presupuesto ejercido por la SCJN* } \\
\hline Año & Presupuesto \\
\hline 2003 & $1^{\prime} 884^{\prime} 909,800$ \\
\hline 2004 & $2^{\prime} 245^{\prime} 382,239$ \\
\hline 2005 & $2^{\prime} 537^{\prime} 078,797$ \\
\hline 2006 & $2^{\prime} 710^{\prime} 929,511$ \\
\hline 2007 & $2^{\prime} 793^{\prime} 058,369$ \\
\hline 2008 & $3^{\prime} 123^{\prime} 665,026$ \\
\hline $2009^{* *}$ & $2^{\prime} 240^{\prime} 680,431$ \\
\hline
\end{tabular}

* En pesos.

** Presupuesto ejercido hasta el 31 de octubre de 2009.

FUENTE: Dirección General de Presupuesto y Contabilidad de la SCJN. 


\begin{tabular}{|l|c|c|}
\hline \multicolumn{3}{|c|}{$\begin{array}{c}\text { Presupuesto asignado a la Suprema Corte } \\
\text { en Estados Unidos y México en 2008 }\end{array}$} \\
\hline \multicolumn{1}{|c|}{ País } & Monto & $\begin{array}{c}\text { Diferencia porcentual entre el } \\
\text { presupuesto estadounidense y } \\
\text { mexicano }\end{array}$ \\
\hline Estados Unidos & $78^{\prime} 727,000$ USD & $300.3 \%$ \\
\hline México & $236^{\prime} 472^{\prime} 892$ USD* & \\
\hline
\end{tabular}

* $1 \mathrm{USD}=13.2094 \mathrm{MXN}$

FUENTE: Federal Funds. Supreme Court of the United States, The Budget for Fiscal Year 2008.

Presupuesto de la Suprema Corte para gastos de promoción

\begin{tabular}{|c|c|c|}
\hline \multicolumn{2}{|c|}{$\begin{array}{l}\text { Presupuesto para servicios de impre- } \\
\text { sión, grabado, publicación, difusión e } \\
\text { información } *\end{array}$} & $\begin{array}{c}\text { Presupuesto para comunicación } \\
\text { social* }\end{array}$ \\
\hline Año & $\begin{array}{c}\text { Presupuesto modificado } \\
\text { total }\end{array}$ & Presupuesto modificado total \\
\hline 2003 & $17^{\prime} 929,400$ & $\overline{-}$ \\
\hline 2004 & $55^{\prime} 050,659$ & E \\
\hline 2005 & $48^{\prime} 323,564$ & $12^{\prime} 051,703$ \\
\hline 2006 & $69^{\prime} 604,989$ & $20{ }^{\prime} 835,800$ \\
\hline 2007 & $27^{\prime} 394,211$ & $17^{\prime} 809,573$ \\
\hline 2008 & $36^{\prime} 475,815$ & $10^{\prime} 907,253$ \\
\hline 2009 & $50 ’ 330,882$ & $26^{\prime} 788,900$ \\
\hline
\end{tabular}

\section{* En pesos.}

FUENTE: Dirección General de Presupuesto y Contabilidad de la SCJN.7

7 3,600 Servicios de impresión, grabado, publicacion, difusión e información.

3,602-1 Impresión y elaboración de publicaciones oficiales y de información en general para difusión.

Asignaciones destinadas a cubrir el costo de las impresiones y publicaciones oficiales que requiera la Suprema Corte, tales como: credenciales impresas, anuncios en los periódicos, avisos de interés general, esquelas en periódicos, etc.; así también, los gastos de información de índole diversa que se realicen en el desempeño de funciones oficiales, tales como: la emisión de folletos, boletines, trípticos, revistas, libros, etcétera. Distintos a los señalados en las partidas 3602-2 impresión y elaboración de publicaciones oficiales y de información en general para difusión. Encuadernación y 3602-3 impresión y elaboración de publicaciones oficiales y de información en general para difusión. Edi- 
Este presupuesto se refiere al gasto directo en difusión. No incluye otro tipo de gastos que pueden generar una percepción positiva o negativa en ciertos actores, como gasto en murales, pago de honorarios para elaboración de libros u otro gasto de representación social.

El exceso de gasto de la Corte es probablemente contraproducente en sí mismo porque manda una imagen de distancia con la sociedad que la financia. Sus altos salarios son la muestra más conspicua de esto. Una Corte más austera, sin duda, tendría una mejor imagen, pues sería mucho más consistente con la premisa de la que parte: impartir justicia.

El tema de cuáles son los elementos que le dan credibilidad a un tribunal es muy complejo. Sin embargo, creemos que resolver algunas cuestiones formales, tanto en el proceso de elección de ministros como en la toma de decisiones del pleno, podrían ayudar a construir una Cor-

ciones. 3602-2 impresión y elaboración de publicaciones oficiales y de información en general para difusión. Encuadernación. Asignaciones destinadas a cubrir el costo de la encuadernación de las impresiones y publicaciones oficiales de la Dirección General de la Coordinación de Compilación y Sistematización de Tesis de la Suprema Corte, tales como: Semanario Judicial de la Federación, Índice semestral, Jurisprudencia por contradicción de Tesis, serie de debates del Pleno de la Suprema Corte, Informe anual y anexo estadístico, apéndices del Semanario Judicial de la Federación y gacetas en diversos tomos, empastado de libros e informes diversos, etcétera.

3602-3 Impresión y elaboración de publicaciones oficiales y de información en general para difusión. Ediciones.

Asignaciones destinadas a cubrir el costo de la edición de las impresiones y publicaciones oficiales de la Dirección General de la Coordinación de Compilación y Sistematización de Tesis de la Suprema Corte, tales como: Semanario Judicial de la Federación y su Gaceta, índice semestral, Informe anual y anexo estadístico, Jurisprudencia por contradicción de Tesis, serie de debates del Pleno de la Suprema Corte, Apéndice de Jurisprudencia, Código Civil y su interpretación por el Poder Judicial de la Federación, Constitución Política de los Estados Unidos Mexicanos, Historia de la Suprema Corte de Justicia de la Nación, producción de C.D. ROM, etcétera.

3603-1 Inserciones y publicaciones oficiales para licitaciones públicas y trámites administrativos en cumplimiento de disposiciones jurídicas.

Asignaciones destinadas a cubrir el costo de los servicios de publicación de edictos, informes, anuncios y otros trámites que en cumplimiento a las disposiciones jurídicas debe publicar la Suprema Corte, así como en materia de licitaciones públicas para la adquisición o enajenación, bases, convocatorias y demás publicaciones relacionadas con los procedimientos de licitación y subastas, la información en el Diario Oficial de la Federación, entre otros. Excluye las licitaciones relacionadas con obras públicas, las cuales se deben prever en la partida 6107-1 servicios relacionados con obras públicas. 
te con mejor percepción social y más legítima, aunque ciertamente no sea lo único.

\section{REGLAS EN LA ELECCIÓN DE MINISTROS}

Las reglas formales en la elección y permanencia en el cargo de los ministros tienen cuatro características:

1. A diferencia de otras partes del mundo, donde sólo hay un candidato, el Ejecutivo federal presenta una terna al Senado, el cual aprueba el nombramiento por dos terceras partes de los senadores presentes;

2. El nombramiento tiene duración de 15 años con un sueldo alto;

3. Incluye una pensión vitalicia similar al sueldo sin restricciones en su ejercicio profesional;

4. El presidente de la Corte es electo por los miembros de la misma.

En este apartado analizaremos cada una de estas reglas formales y determinaremos cómo impactan en la calidad y legitimidad del máximo tribunal del país.

\section{Proceso de elección de los ministros}

De acuerdo con el artículo 96 de la Constitución, el proceso de elección de los ministros tiene dos aspectos centrales:

1. El presidente de la República propone una terna al Senado y éste debe elegir a uno de los candidatos propuestos por mayoría calificada;

2. Si el Senado rechaza la totalidad de la terna propuesta, el Ejecutivo enviará una nueva. Si en esta segunda terna tampoco se logra el nivel de consenso requerido, el presidente de la República designará, dentro de esta misma terna, a la persona que ocupará el cargo.

Las reglas de elección sólo se pueden explicar en el contexto político en el que se aprobó la reforma constitucional de diciembre de 1994. El hecho de que el nombramiento de los 11 ministros se hiciera al mismo 
tiempo — dado que con dicha reforma se removió a los 21 ministros que conformaban este tribunal- hacía difícil, en términos políticos, que el presidente simplemente mandara 11 candidatos por separado. La terna fue un mecanismo que aminoró la percepción de que el ex presidente Ernesto Zedillo estaba conformando una Corte a su modo. Al mismo tiempo, si las cosas no salían bien, el presidente siempre podía tener la última palabra. Es decir, si en dos ocasiones el Senado rechazaba la terna, el Ejecutivo podía nombrar libremente al ministro de su preferencia. Se trataba de conformar un nuevo tribunal con mayor legitimidad, pero, al mismo tiempo, de no renunciar de forma absoluta al control del Ejecutivo en el sistema de nombramientos.

En esos años, el partido del presidente tenía aún la mayoría de los votos en ambas cámaras, pero carecía de los dos tercios requeridos para ratificar el nombramiento. Había que consensar dichos nombramientos con el PAN. Por ello, si bien la mayoría de los nombramientos fueron del presidente, éste tuvo que negociar algunos lugares para candidatos emanados del PAN. El resultado fue una Corte donde predominaban ministros vinculados con el viejo régimen y que tenían la confianza del PRI. ${ }^{8}$ El peso del PRI en la selección de Ministros continuó en el gobierno de Fox ya que en esa administración predominaron candidatos cercanos al PRI. ${ }^{9}$

Con un panorama distinto al de otros países, en la configuración de la Corte no se apostó por un tribunal constitucional para la democracia, sino uno que permitiera atender los problemas de la naciente pluralidad política de la última fase del régimen autoritario. Ello explica, quizá, por qué ex el presidente Zedillo optó por designar principalmente ministros que se hubiesen desepeñado como jueces por varios años. La sola idea hubiese sido impensable en la Europa de los años posteriores a la segunda guerra. Como señala Marian Ahumada, "sobre los jueces ordinarios (en Europa) pesaba el lastre de la etapa anterior; justificadamente o no, la tendencia será considerarlos instituciones vinculadas con el régimen pasado y, en esa medida, un poder potencialmente resistente al cambio". ${ }^{10}$

8 Magaloni, Beatriz et al., Activists vs. Legalists: The Mexican Supreme Court and its Ideological Battleships, mimeo, pp. 24 y ss.

9 Idem.

10 Ibidem, p. 45. 
En franco contraste, en el caso de México no había razones para pensar que se requería era un tribunal constitucional conformado por ministros encargados de marcar la diferencia entre un régimen político autoritario y una democracia constitucional en forma. Más bien, había necesidad de mantener alguna continuidad con el pasado. Los ministros con experiencia judicial eran una apuesta razonable para lograr este objetivo.

Este proceso de continuidad y no de ruptura con el pasado es más notorio en el tipo de argumentación jurídica de las sentencias de la Corte. En los primeros y decisivos años de funcionamiento de los tribunales constitucionales europeos, se puede apreciar un fenómeno distintivo en el tipo de argumentos y construcción de significados de la Constitución más propio de la retórica deliberativa que de la clásica retórica judicial. ${ }^{11}$ En México, en cambio, este fenómeno se ha dado a cuenta gotas y con calidad muy diversa. Para la mayoría de los ministros es más familiar colocarse en el papel de jueces ordinarios y concebir que su función es decidir casos, que verse como máximos jueces del país encargados de fijar las reglas constitucionales que prevengan y eviten la aparición de conflictos similares en el futuro. Además, ha tomado mucho tiempo, y aún no se puede observar con toda claridad, que la Corte ponga en un primer plano la preocupación sobre el impacto económico, social o político de sus decisiones hacia el futuro.

Esta inercia conceptual con el pasado puede explicar que, desde la reforma del 94, los ministros ni siquiera han detectado el problema de que la mayor parte de la jurisprudencia constitucional se generó bajo las coordenadas de un sistema político autoritario y que, por tanto, se requiere una profunda revisión de lo que hoy, en un contexto democrático, deberían ser los criterios de interpretación constitucional. ${ }^{12}$

Evidentemente, conforme el país se democratizó y el poder se descentralizó, las reglas constitucionales fijadas en 1994 para la sustitución de ministros han mostrado sus debilidades. El proceso de designación de

11 Al respecto, véase Ahumada, Marian, op. cit., nota 2, p. 44.

12 Para el caso de la jurisprudencia en materia penal, véase Magaloni, Ana Laura y Ibarra, Ana María, "La configuración jurisprudencial de los derechos fundamentales. El caso del derecho constitucional a una defensa adecuada", Cuestiones Constitucionales, México, núm. 19, 2008, pp. 107 y ss. Para el caso de cómo la antigua jurisprudencia en materia fiscal llevó a una floreciente industria véase Elizondo Mayer-Serra, Carlos, "La industria del amparo fiscal”, Política y gobierno, México, CIDE, vol. XVI, núm. 2, 2009, pp. 349-383. 
ministros cada vez es más complejo y politizado. En la medida que el presidente presente ternas, el Senado puede negociar entre los candidatos propuestos. ${ }^{13}$

El sistema de ternas obliga a los tres candidatos a ministro a competir entre ellos para lograr los apoyos requeridos, lo cual puede tener un efecto negativo en la fortaleza e independencia del máximo tribunal. El ministro Azuela lo explica con claridad: "las ternas llevan a debate y consensos políticos que pudieran traducirse en que después se reclamen los apoyos que se dieron para que la persona saliera". ${ }^{14}$ Un sistema de nombramiento en donde el presidente propusiera a un solo candidato y que éste tuviese que ser ratificado por mayoría calificada del Senado sería mucho mejor para aminorar la politización del nombramiento $\mathrm{y}$, al mismo tiempo, generaría un debate público más amplio y profundo sobre los méritos y cualidades del candidato propuesto.

Para los principales actores en el proceso, la importancia de estos nombramientos está fuera de duda. Por ello, hay intercambios entre los partidos políticos para designar gente que les sea cercana en el puesto. Sin embargo, sigue siendo un asunto con relativa poca atención de los medios de comunicación, con lo cual no se da el escrutinio suficiente sobre el desempeño pasado, autonomía y probidad de los candidatos.

Este proceso de elección de ministros contrasta con el de Estados Unidos. Primero en la forma en que se decide. En el caso estadounidense no hay terna. El presidente, de acuerdo con el artículo 2o. de la constitución tiene el poder para nombrar, con "la asesoría y consentimiento del Senado" al candidato de su preferencia. Ni siquiera hay requisitos para el cargo.

Ello permite que el presidente tenga mayor control sobre el proceso. Sólo puede quedar el que propone. El Senado puede rechazar cualquier propuesta del presidente, lo que le obliga a este último a presentar a un nuevo candidato. Sin embargo, el proceso de designación sólo involucra a un candidato, lo cual inhibe el tipo de politización que tiene el sistema

13 Aunque esto no es la única salida posible. El presidente podría proponer ternas conformadas por personas que les son cercanas, pedir a su partido que tiene más de un tercio de los Senadora vote en contra y luego imponer un candidato. Esto tendría sin duda un costo político alto en su relación con el Senado, pero es una opción que no debiera pasar desapercibida.

14 Reforma, 19 de noviembre de 2009, p. 8. 
de ternas. Además, dado que los nombramientos son vitalicios, la designación difícilmente involucra dos vacantes o más. Ello ayuda a evitar transacciones o intercambios políticos como los que vemos en México.

Ello no significa que no exista politización en los nombramientos de los Justices de la Corte Suprema estadounidense. Después de más de doscientos años de experiencia, se sabe que la ideología de los jueces cuenta mucho para predecir el sentido de sus fallos. Lo han vivido con claridad en los temas torales que ha decidido su Corte a lo largo de su historia. Por ello, el escrutinio de los candidatos es muy riguroso y, evidentemente, la elección de un Justice refleja el tipo de equilibrios políticos entre los republicanos y los demócratas. Cuanto más senadores existan de uno u otro partido, se eligirá a un Justice más liberal o más conservador. Sin embargo, más allá de la ideología del Justice designado, es muy difícil que llegue alguien que carezca de méritos importantes para el puesto. ${ }^{15}$

El contraste con México es interesante. Aquí no existe un escrutinio riguroso pero sí una gran politización. A diferencia de lo que sucede en Estados Unidos, nadie tiene mucha claridad sobre la ideología de los candidatos, lo que se esperaría de sus resoluciones, ni cuál es el papel que debería desempeñar la Corte en el proceso de consolidiación democrática. Sin estas definiciones, lo que se puede esperar es que quien ocupe el puesto de ministro no sea necesariamente el que tenga los mayores méritos o refleje mejor la ideología que defienden los partidos, sino el que haya construído la mejor red de apoyos políticos que, como señala Azuela, después mermen su independencia e imparcialidad.

\section{La duración del cargo}

En México, el cargo de un ministro dura 15 años. Este es un esquema intermedio entre lo que sucede en Estados Unidos - en donde el cargo es vitalicio - y lo que sucede en Europa — en España y Alemania el cargo es por nueve años-.

La experiencia comparada permite constatar las ventajas que tiene que el cargo de ministro sea temporal y no vitalicio. Mientras que en Estados Unidos la Corte se mueve ideológicamente mucho más lento que las

15 Aunque nada garantiza que el nombrado se comporte de la forma esperada, este fue el caso con Sauter quien fue nombrado con la expectativa de que fuera un conservador sólido y que terminó de aliado del bloque liberal. 
preferencias electorales de los estadounidenses, en Europa, los tribunales constitucionales se ajustan más rápido a dichos cambios. Ello, según señala Víctor Ferreres, hace que la falta de legitimidad democrática de los jueces constitucionales sea un problema menos acentuado en Europa que en Estados Unidos. ${ }^{16}$

La segunda ventaja de los nombramientos temporales, sobre todo en el caso de México, es que mantiene abierto el debate sobre qué tipo de Corte necesitamos. El hecho de que, como señalamos, la Corte haya sido una institución que se diseñó e implementó en las postrímerías de un régimen autoriario, ha inhibido el debate que se dio en otros países respecto del sentido y significado de la jurisducción constitucional en un régimen democrático. El hecho de que cada tres años existan dos vacantes para el puesto de minstro puede ir generando las condiciones para que se dé ese debate. Poco a poco, quizá, podremos perfilar de mejor manera el tipo de ministro que se requiere para emular las mejores prácticas de la jurisdicción constitucional en el mundo.

\section{Pensión vitalicia sin restricciones para su ejercicio profesional}

El problema del retiro de los ministros no está en la temporalidad de su mandato, sino en que las normas constitucionales no aseguran que éste sea el último cargo al que pueden aspirar. En efecto, la Constitución permite que los ministros que se retiran puedan ascender inmediatamente a otro cargo público, salvo que se trate del de secretario de Estado, procurador federal o del Distrito Federal, senador federal, diputado federal o gobernador. Para aspirar a alguno de estos cargos, los ministros retirados sólo tienen que esperar dos años desde la fecha en que dejan el cargo. Es decir, los ex ministros pueden pasar de la arena jurisdiccional a la política casi sin ninguna restricción. También pueden optar por litigar desde un despacho, después de transcurridos dos años desde la fecha de su retiro, aprovechando su experiencia y red de contactos al interior del propio Poder Judicial.

El problema no es menor. El esquema de retiro de los ministros está directamente relacionado con el ejercicio cotidiano de su independencia. Si la principal tarea de la Corte es arbitrar conflictos entre poderes pú-

16 Ferreres, Víctor, Justicia constitucional y democracia, Madrid, Centro de Estudios Políticos y Constitucionales, 1997, pp. 42-45. 
blicos y dirimir controversias entre las fuerzas políticas del país, resulta elemental garantizar que no exista la menor sospecha de que el sentido de los votos de los ministros pueda estar motivado por las aspiraciones políticas o profesionales futuras que tengan algunos de sus miembros. El hecho de que el marco normativo no garantice que el cargo de ministro sea el último cargo público al que se puede aspirar, vulnera los cimientos sobre los que se construye la libertad de cada uno de los jueces constitucionales para decidir asuntos de forma independiente.

El problema no termina ahí. De acuerdo con el diseño del esquema de retiro de los ministros, la pensión vitalicia es una especie de "derecho adquirido". Es decir, la pensión se pagará mes con mes sin importar si el ex ministro ya tiene otro cargo público o se haya convertido en un prominente litigante.

Todo ello nos coloca en el peor de los mundos. La única justificación posible para que a un ex ministro se le pague una pensión vitalicia tiene que ver con que ello permite que no ocupe otro cargo público ni se dedique a litigar. Es decir, las pensiones sirven para fortalecer la autonomía e independencia del máximo tribunal.

No se necesita demasiada imaginación para resolver este problema. Existen dos opciones: se reforma la Constitución para que el cargo de ministro sea el último cargo público al que se aspire, o bien, se elimina el derecho a cobrar una pensión vitalicia a todo aquel ex ministro que decide ocupar otro cargo público. Lo primero ayudaría a fortalecer la independencia del máximo tribunal. Lo segundo es una cuestión de racionalidad elemental en el ejercicio del gasto público.

\section{Elección del presidente de la Suprema Corte}

En el caso de México, de acuerdo con el artículo 97 de la Constitución, el ministro presidente es electo por sus pares. "Cada cuatro años, el pleno elegirá de entre sus miembros al presidente de la Suprema Corte de Justicia de la Nación, el cual no podrá ser reelecto para el periodo inmediato posterior".

El que su mandato esté limitado y que sea producto de una elección interna le lleva a tener una influencia acotada. Sabe que, después de cuatro años, regresará a ser un ministro más. 
Con todo, es un Presidente poderoso, pues controla el Consejo de la Judicatura Federal, con lo cual, tiene una enorme influencia en el aparato de justicia federal en general. Cabe recordar que en la reforma original del ex presidente Ernesto Zedillo, en la composición el Consejo de la Judicatura Federal los miembros designados por la Suprema Corte no tenían mayoría, con lo que se acotaba el poder mismo del Presidente de la Corte en este ámbito. Sin embargo, esto fue materia de una reforma constitucional posterior y que se presentó por la presión que los ministros de la Corte sentían de perder el control del Poder Judicial.

En el caso de Estados Unidos, el poder del Chief Justice es mucho mayor, ya que el Senado, a propuesta del presidente, lo nombra cuando el anterior se retira o muere. Un Chief Justice con cargo vitalicio tiene un gran poder y de hecho la Suprema Corte en Estados Unidos históricamente se asocia al papel que ha tenido su presidente.

\section{CÓMO DECIDE LA CORTE}

La forma es fondo. Esto ha quedado demostrado en el amplio debate teórico y empírico sobre cómo se eligen a los jueces y cómo actúan. En los últimos quince años, la discusión académica en torno a lo que se conoce como procedural fairness o procedural justice (justicia por procedimiento), ha demostrado que el proceso de elección de los miembros del Poder Judicial, así como el proceso por el cual los jueces llegan a sus decisiones, influye en el resultado y percepción social de las mismas.

Uno de los grandes hallazgos de este debate es que la aceptación social y la percepción de justicia que se tenga de las decisiones judiciales no sólo dependen del contenido de las mismas, también están correlacionadas positivamente con la forma o proceso a través del cual los jueces llegan a ellas y de la legitimidad con la que se perciben tienen para tomar estas decisiones. En la medida en que el proceso se percibe como legítimo, las sentencias serán más aceptables por el público. Lo legítimo no tiene necesariamente que ser lo correcto, pero ese es otro tema. ${ }^{17}$

17 Para una revisión de los estudios y los hallazgos más importantes de este debate sobre procedural fairness, véase MacCoun, Robert, J., "Voice, Control and Belonging. The Double-Edged Sword of Procedural Fairness", Annual Review of Law and Social Science, vol. 1, 2005. 
El proceso de decisión del Pleno de la Corte de nuestra Suprema Corte de Justicia tiene tres características centrales que la distinguen de la mayoría de las cortes supremas y tribunales constitucionales:

1. Asignación de casos a partir de un sistema aleatorio;

2. Amplia publicidad del debate y deliberación entre los ministros y,

3. Audiencias informales privadas entre ministros y quejosos (el conocido "alegato de oído o de oreja").

Estas tres características, en nuestra opinión, impactan negativamente en la calidad, claridad y legitimidad de las sentencias de nuestro máximo tribunal. A continuación analizaremos cada una ellas por separado y haremos una comparación con lo que sucede en otras tradiciones jurídicas, en particular la de Estados Unidos, dado que nuestra Suprema Corte fue inspiración clara de su Corte ${ }^{18}$ y es la más antigua y más estudiada del mundo.

Cabe señalar que nuestra Corte tiene una carga de trabajo mucho mayor a la de Estados Unidos. Esto es así, en buena medida, porque los Tribunales Colegiados son vistos como una corte de apelación más y no como el punto final del debate, salvo excepciones que la propia Corte decide o no atraer. En el caso de Estados Unidos, en 2008, la Corte recibió 7,868 solicitudes de revisión, pero sólo se aceptaron $87 .{ }^{19}$

Dada la enorme carga de trabajo, nuestra Corte opera en dos salas, además de en pleno. La Corte de los Estados Unidos siempre opera en Pleno.

18 Esto se observa hasta en la traducción, pues no es Corte Suprema, sino la traducción literal de Suprema Corte. Es como si dijéramos Constitucionales Tribunales. Para un análisis de la tensión entre el modelo de Estados Unidos como inspiración de nuestra forma de gobierno y el europeo continental en lo que se refiere a la tradición jurídica mexicana véase Hale, Charles, "La tradición del derecho constitucional europeo y el constitucionalismo en el México del Siglo XX: el legado de Emilio Rabasa", Las Constituciones de la República Mexicana, México, El Colegio de México, 2007, pp. 75-101.

19 “The Statistics", Harvard Law Review, vol. 123, núm. 1, noviembre de 2009. 


\section{Asignación de casos con base en la suerte o el azar}

En 2007, el Pleno realizó 122 sesiones públicas en las que resolvió 313 asuntos. ${ }^{20}$ Durante 2008 se llevaron a cabo 118 sesiones públicas, 114 ordinarias y cuatro extraordinarias, en las cuales la Corte resolvió 178 asuntos. ${ }^{21}$ Los asuntos que llegan al Pleno son asignados a un determinado Ministro a partir de una lista preestablecida. Dicha lista determina un orden secuencial entre ministros. El ministro al que le "toca" el asunto tiene que elaborar el proyecto de sentencia que en su momento discutirán los once ministros. ${ }^{22}$

Este mecanismo asegura una distribución equitativa del número de asuntos a resolver por cada ministro, aunque no necesariamente garantiza la equidad en la importancia o grado de dificultad que los casos conllevan. A un Ministro le pueden tocar, por azar, los asuntos más controversiales o complejos, mientras que a otro meramente los casos triviales o irrelevantes. Con todo, es la suerte la que decide. ${ }^{23}$

A cambio de esta equidad en el número de asuntos a resolver, y la aleatoriedad en su importancia, el método de asignación inhibe o dificulta el consenso entre los ministros respecto al sentido final de la sentencia. Cuando se asigna un asunto a un ministro determinado con bases aleatorias no es relevante la posición jurídica del ministro respecto del caso a resolver. Tampoco lo es el grado de acuerdo o discrepancia que existe entre los miembros del tribunal. El ministro que proyecta la sentencia puede estar con la mayoría o estar en clara minoría. El proceso por el que se asignan los casos ni siquiera permite saber esto ex ante. Es decir, el

20 Ortiz Mayagoitia, Guillermo, Informe de labores del Poder Judicial de la Federación 2007, 14 de diciembre de 2007.

21 Ortiz Mayagoitia, Guillermo, Informe de labores del Poder Judicial de la Federación 2008, 12 de diciembre de 2008.

22 No todos los proyectos de sentencia se asignan de esta manera. Cuando la Corte se encuentra en período de receso, el ministro que se queda de "guardia" es el que elabora los proyectos de sentencia de todos los casos que lleguen en ese tiempo. También se ha dado el caso que cuando llega a la Corte un asunto que los ministros consideran muy importante o que tiene gran cobertura mediática se ha decidido asignar la redacción del proyecto de sentencia a un conjunto de varios secretarios de estudio y cuenta de diferentes ministros.

23 Aunque este método puede ser manipulado de no registrarse en orden riguroso los asuntos que llegan. 
Ministro elabora su proyecto sin conocer previamente la opinión jurídica de sus compañeros de tribunal. De hecho no se circula el material entre sus pares, muchas veces éste se presenta ante el Pleno sin siquiera una lectura por parte de los ministros.

Un mecanismo de esta naturaleza tiene cierta lógica desde la concepción formalista respecto a la naturaleza de la función jurisdiccional. Desde esta concepción, la función del juez es simplemente la de aplicar al caso concreto el derecho preexistente, el cual siempre es claro, unívoco e incontrovertible. El derecho se entiende como el álgebra y, por tanto, la labor jurisdiccional consiste simplemente en despejar una ecuación. En este sentido, no es relevante la posición jurídica del ministro respecto del asunto a resolver. Cualquiera que fuese el ministro que proyectara el asunto, dados sus conocimientos técnicos, llegaría a un veredicto final similar. Por tanto, el proceso de asignación de casos lo único que tiene que garantizar es que las cargas de trabajo entre los ministros sean lo más equitativas posibles.

Sin embargo, todos sabemos que el derecho, más aún en el ámbito constitucional, rara vez es claro, unívoco e incontrovertible. Prueba de ello son los frecuentes votos concurrentes y disidentes de los propios ministros. Cada uno de los miembros del máximo tribunal tiene, ineludiblemente, su propia ideología, sus prejuicios, su forma de entender la Constitución y su manera particular de concebir y desempeñar la función de juez constitucional. En la medida en que estas divergencias ideológicas y conceptuales entre los ministros encuentren puntos de consenso y de unidad, las decisiones de la Corte tendrán mayor claridad, contundencia y grado de autoridad hacia el futuro. ${ }^{24}$

Las decisiones de la Corte que se toman por una estrecha minoría y en donde existen varios votos concurrentes y disidentes sólo reflejan las distintas posiciones jurídicas e ideológicas de los miembros que lo inte-

24 La relevancia de emitir decisiones judiciales lo más unánimes posibles tratándose de los tribunales que funcionan en forma colegiada ha sido ampliamente analizada por la academia jurídica de Estados Unidos. Sobre el tema, véase, entre otros: Davis, J. y Reynolds, W., "Judicial Cripples: Plurality Opinions in the Supreme Court", Duke Law Journal, 1974, vol. 59, pp. 59 y ss.; así como Gerhardt, M., "The Role of Precedent in Constitutional Decision Making", George Washington Law Review, vol. 60, 1991, pp. 120 y ss. 
gran. ${ }^{25}$ Con ello, la fuerza y autoridad del órgano jurisdiccional como tal se diluye. Este tipo de sentencias constata que los ministros no logran ponerse de acuerdo sobre el sentido y alcance de los preceptos constitucionales en cuestión. Por tanto, la función de la Corte de establecer los criterios de interpretación constitucional vinculantes para el resto de los tribunales, y con ello impactar en la futura acción de gobierno, se ve disminuida. ${ }^{26}$

Un ejemplo paradigmático de decisiones divididas fue el caso de la controversia constitucional en materia energética. En ese asunto, las cámaras de Senadores y de Diputados promovieron una controversia demandando la invalidez de los artículos 126 y 135 del Reglamento de la Ley de Servicio Público de Energía Eléctrica. Dichos preceptos reglamentaban la venta de excedentes de los proyectos de autoabastecimiento y cogeneración de electricidad a la Comisión Federal de Electricidad. El argumento central de la demanda era que el reglamento iba más allá de la ley y que, por tanto, el Ejecutivo había invadido las competencias del Congreso.

La sentencia final fue particularmente dividida: ocho ministros estimaron que el reglamento violaba la Constitución, sin embargo, cinco de ellos consideraron que era inconstitucional por violar los artículos 25 , 27 y 28 de la Constitución, mientras que los otros tres estimaron que la inconstitucionalidad obedecía a una invasión de competencias por parte del Ejecutivo al Congreso. Finalmente, tres ministros emitieron votos disidentes y desestimaron la inconstitucionalidad de los artículos del reglamento impugnados.

25 Además, en el caso mexicano, una minoría estrecha no es suficiente para declarar inconstitucional una norma en el caso de una controversia. La idea es darle deferencia al órgano electo, el Congreso, sobre el designado, la Corte. En estos casos se requiere una mayoría de 8 de 11. Sin embargo, esto lleva a la paradójica de que hay una mayoría, y el público la registra como tal, pero la norma sigue siendo constitucional, al no pasar la mayoría calificada establecida.

26 También en la academia jurídica de Estados Unidos ha sido ampliamente discutido y criticado el problema de las decisiones de la Corte Suprema divididas. Véase, entre otros, Novak, L., "The Precedential Value of Supreme Court Plurality Decisions", Columbia Law Review, 1989, vol. 89, pp. 769 y ss. y Thurmon, M., "When the Court Divides: Reconsidering the Precedential Value in Supreme Court Plurality Decisions", Duke Law Journal, 1992, vol. 43, pp. 448 y ss. 
Una decisión constitucional dividida crea incertidumbre jurídica debido a la impredictibilidad sobre lo que los ministros harán en el futuro en casos análogos o similares. Dicha incertidumbre, en el caso de la sentencia en materia energética, generó que los inversionistas extranjeros fueran más cautos en su decisión de seguir invirtiendo en México y que el Legislador y el Ejecutivo continúen debatiendo cuáles son los límites constitucionales de la regulación en materia de generación eléctrica. Una decisión por consenso de la Suprema Corte habría mandado una señal mucho más clara de dónde nos encontramos en la materia, con lo cual la Corte hubiese desempeñado mejor la función de máximo árbitro en asuntos constitucionales.

En sentido opuesto a la controversia en materia energética estuvo la acción de inconstitucionalidad sobre la Ley de Medios. En este caso, los ministros calibraron con inteligencia la necesidad de emitir una decisión prácticamente por unanimidad. Ello, además de resolver el problema más obvio (la necesidad de contar con ocho de diez votos para invalidar los preceptos de la ley en cuestión dado que el ministro Cossío se excusó de participar en este caso), también atendió otro problema menos evidente: el peso de la autoridad de la Suprema Corte para resolver una disputa que involucraba a grupos tan poderosos. El hecho de que los ministros de la Corte pudiesen hacer a un lado sus discrepancias y emitir una sentencia en la que se escuchara una sola voz, "la voz de la Suprema Corte", dotó a dicha decisión de la contundencia política y jurídica que requería.

Lo que sucedió con la Ley de Medios no es la práctica común de nuestra Suprema Corte. La mayoría de las decisiones que, por su relevancia, han sido materia de amplia difusión mediática, muestran una Corte dividida, en donde la opinión jurídica de cada uno de sus miembros cuenta más que la autoridad del órgano en su conjunto. Así, por ejemplo, la controversia constitucional sobre la facultad de veto del presidente tratándose del Presupuesto de Egresos fue resuelta a favor del presidente por seis votos contra cinco; la controversia constitucional que interpuso la Asamblea Legislativa del Distrito Federal en contra de la decisión de la Cámara de Diputados relativa al desafuero de López Obrador fue resuelta en contra de la Asamblea por siete votos contra cuatro; el caso de Lydia Cacho y el gobernador de Puebla fue una decisión dividida de seis contra cuatro (con la ausencia del ministro Franco) y el asunto relativo al ejercicio de la facultad de investigación de la Corte en relación a los hechos sucedidos el 10 de junio de 1971, conocidos como "El Halcona- 
zo", fue una decisión de siete votos contra cuatro en el sentido que no procedía dicha investigación.

Enfrentar el fenómeno de "decisiones divididas" es más complicado dado el propio proceso de asignación de casos. Éste refleja, a su vez, la dificultad que tienen los ministros para hacerse cargo de las diferencias ideológicas, jurídicas y conceptuales que existen entre ellos.

El método de asignar casos en nuestra Corte contrasta con la forma en la que opera el Tribunal Supremo estadounidense y algunos Tribunales Constitucionales europeos. En el caso de los de Estados Unidos, el proceso para asignar asuntos busca ayudar a mantener unida a la mayoría. Para ello, todos los Justices tienen que estudiar el asunto y asistir a la audiencia oral en donde las partes plantean sus principales argumentos y los Justices, a su vez, les formulan preguntas puntales a los litigantes. Una vez terminada la audiencia, los Justices se reúnen a puerta cerrada para conocer la posición jurídica de cada uno de ellos y determinar en qué sentido pareciera que la mayoría de los miembros del tribunal quiere que sea proyectado el asunto. El proyecto de sentencia se le asigna a uno de los Justices que se encuentran en la mayoría. El presidente de la Corte lo asigna si está dentro de la mayoría. Lo hace de forma discrecional. De no estar el presidente del lado de la mayoría, esta responsabilidad le compete al Justice con más antigüedad que se encuentre en la mayoría.

Este método es una de las fuentes de poder del presidente de la Corte. Él decide quién redacta la sentencia. Puede ser también fuente de manipulación en algunos casos en que el presidente de la Corte se ponga por razones estratégicas del lado de la mayoría para poder él asignar casos importantes a sus aliados o a él mismo y asuntos aburridos y triviales a sus adversarios.

A pesar de los problemas señalados, este método ayuda a iniciar la discusión en el sentido en que, en principio, se inclina la mayoría. Esto también puede permitir, sobre todo en los casos importantes, que el responsable de elaborar la sentencia vaya buscando una redacción que cuente con el apoyo de sus pares. Para ello los borradores del proyecto circulan ampliamente entre los ministros que están con la mayoría. Así, a través del sistema de asignación de casos, la Corte Suprema de Estados Unidos busca incentivar consensos entre sus miembros y generar decisiones que reflejen la "opinión del tribunal" y no los puntos de vista particulares de 
cada uno de sus jueces. Ello es parte intrínseca de su autoridad y legitimidad.

Esto no quiere decir que el método lleve necesariamente al consenso. La Corte Suprema de Estados Unidos también emite decisiones divididas y esto depende mucho de su composición. Recientemente, de hecho, la división entre conservadores y liberales es tan fuerte y polarizada que la mayoría de los casos se resuelven cinco a cuatro y el método de asignación de casos a la presunta mayoría ayuda muy poco. Un Justice, Kennedy, termina por decidir, pues es el llamado swing vote. Esta división ideológica tan clara entre los ministros está deslegitimando sus decisiones y haciendo evidente cuán política es la naturaleza de las mismas. Por lo mismo, ha hecho evidente lo importante que es la nominación de justices por parte del Presidente. ${ }^{27}$

Sin embargo, vale destacar dos cosas: a) el sistema de asignación en función de dónde está la mayoría ayuda a encontrar consensos en ciertos casos y contextos, y b) la opinión pública y el debate académico son muy críticos ante decisiones muy divididas de la Corte Suprema, ya que hace evidente la politización del este cuerpo y su operación con base en principios ideológicos más que jurídicos.

\section{Amplia publicidad del debate y proceso de deliberación de los ministros}

De acuerdo con el artículo 94 de la Constitución, "las sesiones del Pleno y de las salas serán públicas y por excepción secretas en los casos en que así lo exijan la moral o el interés público". Este precepto, desde hace muchos años, fue interpretado por la Corte en el sentido que era obligatorio hacer público el proceso de deliberación entre los ministros. Cualquier ciudadano podía sentarse a escuchar la sesión del Pleno en el recinto donde se llevaba a cabo. Pocos lo hacían y casi nada se reportaba en la prensa.

Esta publicidad potencial de las sesiones del Pleno adquirió una dimensión real y hasta espectacular cuando, en 2006, la Corte optó por difundir sus sesiones a través de la televisión y dar acceso irrestricto, vía Internet, a las versiones estenográficas de las mismas. Por tanto, hoy en

27 Véase Dworkin, Ronald, "The Supreme Court Phalanx", The New York Review of Books, 27 de septiembre de 2007, vol. 54, núm. 14. 
día, cualquier persona puede, a través de ambos mecanismos, conocer y analizar palabra por palabra las discusiones de los ministros y la forma en que cada uno de ellos abordó la cuestión constitucional controvertida.

Además, desde 1995 el pleno de la Corte suspendió la práctica de sesiones privadas previas en la que los ministros solían decidir lo más importante, haciendo de la sesión pública un mero ejercicio de relaciones públicas ante el escaso público y la prensa. Ahora, hasta donde se puede apreciar, los ministros suelen llegar a la sesión del Pleno sin acuerdos previos.

La publicidad del proceso de deliberación y, más significativo aún, con un amplísimo nivel de difusión, puede haber servido, en un momento de transición, para que la Corte adquiriera una mayor visibilidad pública. Sin embargo, no es posible ignorar los costos y problemas que ello genera.

El primero y más obvio es la clara distancia que existe entre lo discutido y la redacción final de la sentencia. Ello genera confusión en el debate público respecto a las razones que da la Corte para alcanzar su decisión. Mientras que en el proceso de deliberación de cualquier órgano jurisdiccional colegiado lo que existe es la confrontación de los distintos puntos de vista de los miembros que lo integran (en este caso los de los once ministros), una sentencia es la traducción de esos puntos de vista en una serie de argumentos jurídicos concatenados y ordenados de manera lógica y comprensible que relajan "la voz" del tribunal.

La amplia publicidad del proceso de deliberación ha hecho que esta distinción entre el proceso de deliberación y la sentencia final se haya desdibujado casi por completo. La opinión pública e inclusive el debate académico tienden a analizar el trabajo de la Corte a través de las versiones estenográficas o del debate televisivo de las sesiones del Pleno y no a partir de la llamada sentencia engrosada, siendo ésta la que tiene valor jurídico.

Desde esa perspectiva, el análisis se centra en dos aspectos principalmente:

1. El sentido final de la decisión, y

2. Las expresiones de cada ministro durante el debate. 
Dado lo anterior, la autoridad de la Corte y su impacto en la vida pública del país tienden a diluirse. ${ }^{28}$ La experiencia exitosa de la jurisdicción constitucional en otros países ha demostrado que la fuerza e impacto de un tribunal constitucional radica principalmente en su capacidad para ir definiendo, casuísticamente, el sentido y alcance de los principios y valores que subyacen en el texto constitucional. Ello lo hace a través de los razonamientos jurídicos de sus sentencias, pues es lo que termina teniendo impacto hacia el futuro en el quehacer público y la vida ordinaria de los ciudadanos.

Dicho de otra manera, es menos relevante hacia el futuro que el tribunal haya invalidado o no determinada ley; lo que cuenta, sobre todo, son las razones que haya dado para llegar a ese veredicto, pues en esas razones se encuentra la construcción del sentido y alcance de los preceptos constitucionales que definen los límites jurídicos del quehacer público. El hecho de que en México se analice la labor de la Corte desde las versiones estenográficas o el debate televisivo coloca en un segundo plano muy remoto la construcción del significado de los preceptos constitucionales que están en los argumentos vertidos en sus sentencias. ${ }^{29}$

El segundo problema que se deriva de esta amplia publicidad de su proceso de deliberación es que inhibe la calidad del debate jurídico entre los ministros. De hecho, en varias sesiones del Pleno, lo que se puede observar es que los ministros llegan con una ponencia escrita sobre su punto de vista del asunto y que una gran parte del tiempo de la sesión consiste en la lectura pública de dichos documentos. El ejercicio no es de carácter deliberativo; no discuten entre ellos. Más bien, cada ministro expresa su opinión particular que el asunto concreto le merece.

Es decir, el debate del Pleno es entendido menos como un debate jurídico entre pares que buscan encontrar una buena solución al caso que

${ }^{28}$ No pasa desapercibido para los autores que la baja calidad de las sentencias de la Corte, en términos de su estructura argumentativa y de su innecesaria excesiva extensión, es un factor que también inhibe que el debate público analice la sentencia engrosada. Sin embargo, nuestro argumento es que la amplia difusión del proceso de deliberación de los ministros, a través de las versiones estenográficas y de la televisión, no puede ser un sustituto de las sentencias, ni tampoco un paliativo para que los ministros dejen de atender las deficiencias argumentativas de sus decisiones.

29 Un tema adicional es cómo se argumenta en México. Lo formal tiene preeminencia sobre lo sustantivo. El uso de citas extensas de los textos legales hace las sentencias de muy difícil lectura y más complicado aún traducirlas al gran público. 
tienen enfrente y más como un foro académico de cara a los medios de comunicación en donde cada ministro externa su propio punto de vista sobre el asunto. Seguramente tener enfrente una cámara de televisión acentúa el impulso de cada uno por hacer notar su individualidad y dificulta la posibilidad de que alguno de ellos rectifique o modifique su posición en aras de alcanzar una decisión que sume voluntades. Finalmente, en el peor de los casos, la televisión y las versiones estenográficas exhiben, innecesariamente, a los ministros que pueden no llegar bien preparados a la sesión o que no han analizado con todo detalle el proyecto de sentencia. ${ }^{30}$

El carácter público del proceso de deliberación de la Corte mexicana es atípico. Los tribunales constitucionales europeos y la Corte Suprema de Estados Unidos discuten sus decisiones a puerta cerrada. Nadie conoce el proceso de deliberación de los máximos jueces constitucionales. Las partes públicas del proceso son dos:

\section{La audiencia oral frente a las partes, y}

2. La audiencia en donde el ministro ponente expone oralmente el veredicto y las principales razones para alcanzarlo y, a veces, también algunos de los votos particulares.

Cabe destacar que, en Estados Unidos, el proceso de deliberación no sólo no es público, sino que está reservado sólo a los nueve justices. En el salón donde deliberan no pueden entrar ni sus asistentes. La idea es dejar a los nueve justices deliberar con toda libertad: que unos y otros se traten de convencer sobre las bondades de sus argumentos o posiciones, que nadie pierda cara porque modificó su argumento o cambió de posición, que abiertamente se discutan las dimensiones políticas, sociales o económicas que plantean los asuntos, así como las ventajas que tiene para la Corte resolver en uno $\mathrm{u}$ otro sentido. ${ }^{31}$

30 Este fue el caso en un cambio crucial a la jurisprudencia en materia de expropiación. Los ministros lo justificaron con base en una interpretación equivocada del Tratado de Libre Comercio de América del Norte, razón por la cual en el engrose se tuvo que justificar de otra manera. Véase al respecto, Elizondo Mayer-Serra, Carlos y Pérez de Acha, Luis Manuel, ¿Un nuevo derecho o el debilitamiento del Estado? Garantía de audiencia previa en la expropiación, México, CIDE, 2009.

31 Esto, sin embargo, deja de funcionar cuando la Corte se polariza por razones ideológicas, como sucede en este momento en el caso de la Corte Suprema de Estados Unidos. Dworkin, op. cit., nota 28. 
El punto central es que un espacio de deliberación privado es fundamental para que los jueces constitucionales puedan encontrar soluciones jurídicas correctas. Si bien los secretarios proyectistas de la Corte Suprema (clerks) pueden enterarse, si sus jefes se lo cuentan, de cómo está el equilibrio de fuerzas al interior del tribunal, ello no suele filtrarse a la opinión pública. El proceso está diseñado para que no se conozcan los argumentos parciales e imprecisos con los que se va construyendo la decisión.

La voz pública de este tipo de tribunales son sus sentencias, que se hacen públicas en forma irrestricta, con todo y los votos concurrentes y disidentes. Es decir, los ciudadanos conocen el producto final del proceso de discusión a través del cual los jueces llegaron a dichos veredictos. Así sucede en todos los países con sistemas de jurisdicción constitucional robustos.

El contraste con el caso mexicano es evidente. Aquí conocemos mucho mejor el proceso de deliberación y la forma en que cada ministro abordó el problema constitucional planteado que la sentencia definitiva. Prueba de ello es que el quehacer de la Corte, en términos de la opinión pública, se analiza casi siempre a través de las sesiones del Pleno y no por medio de las sentencias definitivas. Este es el mundo al revés en términos de los asideros de legitimidad y fortaleza de los tribunales constitucionales o cortes supremas en el mundo.

\section{Reuniones en lo oscurito con los quejosos}

El tercer problema se refiere a la relación de los ministros con los quejosos. En México, a diferencia de lo que ocurre prácticamente en cualquier democracia consolidada, una de las partes se puede reunir en privado con el juez sin que esté presente la otra y sin que lo sepa. En nuestro país esto forma parte de la "cultura judicial" que parece obvia y lógica, al punto que nadie se percata de los problemas que ello plantea en términos de la percepción de los justiciables y de los ciudadanos respecto de la imparcialidad e incorruptibilidad del juez.

Así, los ministros, como el resto de los jueces del país, tienen reuniones privadas en sus oficinas con los quejosos sin que esté presente la contraparte. Este "cabildeo" de los quejosos, si se puede llamar así, no se encuentra debidamente institucionalizado, aunque varios ministros han 
establecido un día fijo para recibir en sus oficinas a los distintos quejosos. ${ }^{32}$

La institucionalización en la "nueva" Suprema Corte del denominado "alegato de oreja o de oído" del pasado revela que los ministros no se han hecho cargo cabalmente de la historia autoritaria que les antecede. Las reglas, formales e informales, que guiaban la relación de los ministros con los quejosos en el contexto de un régimen autoritario no se modificaron con el nuevo contexto político del país.

Aunque hay casos donde los ministros han optado por celebrar una consulta pública para ver los argumentos de las partes, incluidos ciudadanos interesados en el tema, como se ha visto en la controversia en torno a la despenalización del aborto, éstos son casos excepcionales. Además, ello no implica que quede desterrado el "alegato de oreja".

Esto no tiene que ver con el hecho de que México no tiene un sistema de justicia oral. En los regímenes democráticos, las reuniones privadas entre jueces y justiciables están expresamente prohibidas. Éstas menoscaban la percepción sobre la incorruptibilidad e imparcialidad de los jueces y, en este sentido, debilitan los cimentos mismos de un Estado de derecho. Tratándose del caso de los máximos jueces del país, resulta aún más delicada esta práctica judicial propia de un régimen autoritario y poco transparente.

Nuevamente, el contraste con otros países es revelador. Prácticamente en todos los países en donde existen códigos de ética judicial, está prohibido que el juez se reúna con alguna de las partes en privado. Tal es el caso de Estados Unidos, a nivel federal ${ }^{33}$ y local, y de muchos otros paí-

32 Para quien quiera ahondar sobre esta práctica sui géneris de la justicia mexicana, a través de los mecanismos que da la Ley de Transparencia, quizá es posible saber con quién y a qué horas se reúne en privado cada uno de los ministros.

33 Code of Conduct for United States Judges. Canon 3. A judge should perform the rutines of the office impartially and diligently... A. Adjudicative Responsibilities... (4) A judge should accord to every person who is legally interested in a proceeding, or the person's lawyer, full right to be heard according to law, and, except as authorized by law, neither initiate nor consider ex parte communications on the merits, or procedures affecting the merits, of a pending or impending proceeding. A judge may, however, obtain the advice of a disinterested expert on the law applicable to a proceeding before the judge if the judge gives notice to the parties of the person consulted and the substance of the advice, and affords the parties reasonable opportunity to respond. A judge may, with consent of the parties, confer separately with the parties and their counsel in an effort to mediate or settle pending matters... 
ses. Cabe mencionar dos: Honduras ${ }^{34}$ y Venezuela. ${ }^{35}$ España, Portugal, Cuba, Brasil, Colombia, Uruguay, Chile y otros estados miembros de la Cumbre Judicial Iberoamericana, decidieron suscribir en forma conjunta el Código Iberoamericano de Ética Judicial, cuyo artículo 15 expresamente proscribe las reuniones privadas entre juez y parte. ${ }^{36}$

En claro contraste con nuestro caso, en Estados Unidos la parte del proceso que sí es pública es el alegato oral de los quejosos. Es el único momento, a la vista de todos, donde se pueden ver los quejosos con los justices y que sirve para que éstos conozcan el problema central que está en juego, a juicio de los involucrados.

Incluso, la menor sospecha de conflicto de interés, como el tener en su portafolio de inversiones acciones de una empresa que tiene un litigio en la Corte, lleva a que los ministros se excusen de participar. ${ }^{37}$ En México este tema no se ha desarrollado aún.

\section{CONCLUSIONES}

Los ministros aún no logran hacer de la Corte un órgano con capacidad para articular el sentido y alcance de los preceptos constitucionales hacia la sociedad y el futuro. La Corte no ha logrado trascender los mecanismos en el nombramiento de jueces y las prácticas de operación propia de la Corte en los años donde el Ejecutivo dominaba la escena

34 Código de Ética para Funcionarios y Empleados Judiciales. Acuerdo número 558. Artículo 2o. El Magistrado o Juez debe ejercer su cargo con integridad, por tanto, debe obrar con honestidad, independencia, imparcialidad y ecuanimidad. A este efecto, deberá: a) Abstenerse de conceder audiencias privadas a cualquier persona que pretenda influir en sus decisiones, afectando su independencia o imparcialidad...

35 Código de Ética Profesional del Abogado Venezolano. Artículo 52. Constituye una grave infracción ética sostener comunicaciones privadas con los jueces, fiscales del Ministerio Público u otros funcionarios, en ausencia del abogado de la parte contraria, en relación con un juicio pendiente, o de asunto que se gestione.

36 Código Iberoamericano de Ética Judicial. Artículo 15. El juez debe procurar no mantener reuniones con una de las partes o sus abogados (en su despacho o, con mayor razón, fuera del mismo) que las contrapartes y sus abogados puedan razonablemente considerar injustificadas.

37 No siempre es así de estricto. No hay regla. Es un asunto moral que depende del ministro. En casos altamente politizados, como en Bush vs. Gore, nadie se excusa. 
política. Tampoco ha sabido adoptar las formas propias de un sistema democrático.

Ciertamente, la manera en como son electos los Ministros no ayuda a que la sociedad sienta que tienen control alguno en el proceso. Esta tarea corresponde a los legisladores, quienes deberán evaluar si es conveniente el mecanismo vigente, aunque el costo de modificar la Constitución es muy elevado. Además, un mero cambio formal aislado sin haber definido con claridad para qué debe servir la jurisdicción constitucional en una democracia es posible que no tenga el efecto esperado.

Lo que sí sería un cambio constitucional relevante y con el efecto esperado es hacer que el cargo de ministro sea el último cargo público al que se pueda aspirar y que tampoco se permita a los ministros retirados litigar. Una reforma en este sentido fortalecería la independencia del máximo tribunal del país.

También tendría un impacto positivo que la Corte modificara el proceso de toma de decisiones. Son reglas que, como hemos mostrado, son subóptimas y fáciles de cambiar. El azar en la asignación de casos y la amplia publicidad del proceso de deliberación incentivan las decisiones divididas, inhiben un proceso de deliberación profundo y serio entre los ministros y dificultan transmitir a la opinión pública las razones jurídicas que sustentan su veredicto. Por su parte, las reuniones con los quejosos en privado dificultan la construcción de una Suprema Corte con la distancia suficiente de los ganadores o perdedores en sus sentencias y donde la imparcialidad e incorruptibilidad de sus miembros esté fuera de toda sospecha. Si nuestra Suprema Corte, como el resto de los tribunales del país, no incorpora a su quehacer institucional algunas de las prácticas más comunes y aceptadas de las judicaturas en países democráticos, como prohibir reuniones privadas entre alguna de las partes y el juez, verá mucho más difícil la construcción de una legitimidad social más amplia y de largo plazo.

Estas tres características del proceso de decisión de la Corte pueden cambiar si los ministros lo deciden. Por lo que toca al sistema de asignación de casos, cabe destacar que el artículo 14, fracción II de la Ley Orgánica del Poder Judicial de la Federación (LOPJF) otorga al Presidente de la Corte la facultad para designar al Ministro ponente. La lista preestablecida con un orden secuencial entre ministros para asignar casos es una política interna que, como tal, puede cambiarse a través de los 
mecanismos internos que tiene la propia Corte. Lo mismo sucede con el "alegato de oído", pues ésta es una práctica judicial, no una norma legal. Por tanto, bastaría que en el Reglamento Interno de la Corte quedara establecida la prohibición de dicha práctica, y hay evidencia internacional suficiente con qué sustentarla, para que ya no siguiera ocurriendo.

Sin duda, el aspecto que con más dificultad se puede cambiar es la publicidad del proceso de deliberación. El artículo 94 de la Constitución, así como el artículo 6 de la LOPJF, establece que las sesiones del Pleno en donde se resuelven casos concretos serán públicas por regla general. Buscar la aprobación de una reforma constitucional o legal para limitar esta publicidad no parece ser un camino sencillo para la Corte. Sin embargo, dejando las normas como están, la Corte puede actuar en dos direcciones.

En primer término, el Canal Judicial puede dejar de cubrir las sesiones del Pleno y puede eliminarse el acceso irrestricto vía Internet a las versiones estenográficas. Con ello, se incentivaría a la opinión pública y a los académicos a poner atención a las sentencias de la Corte y no sólo al proceso de deliberación.

En segundo lugar, la Corte también podría restablecer la práctica de las sesiones privadas, previas a las públicas, en donde los ministros realmente debatieran y se pusieran de acuerdo sobre las cuestiones jurídicas más importantes que plantea el asunto. Ambos mecanismos podrían ayudar a generar un debate jurídico más abierto y de mayor calidad entre los ministros.

Finalmente, lo que está en juego es la capacidad de nuestra Suprema Corte de pacificar conflictos constitucionales, a la par de intentar que éstos no se sigan presentando en el futuro. En ello la Corte se juega su autoridad y legitimidad. El mecanismo para que la Corte desempeñe este papel son sus sentencias, las cuales deben ser claras, sólidas en términos jurídicos y persuasivas en términos argumentativos. Las decisiones divididas, la tensión entre lo que se dijo en la sesión y lo que dice la sentencia y la sospecha de negociación en lo oscurito inhiben esta función elemental de la justicia constitucional en un régimen democrático.

Unas palabras últimas. El modelo utilizado para comparar nuestra Corte con otras similares puede ser utilizado para ver cómo estos mismos temas afectan o no en el comportamiento de órganos autónomos, como el IFE, la Cofeco, la Cofetel, etcétera. La forma en que se integran y deciden cada uno de estos cuerpos sin duda influyen en su forma de operar. 
Por ejemplo, en la medida que el presidente de la Cofeco es, como en el caso de la Suprema Corte de Estados Unidos, designado al momento del nombramiento presidencial le da mucha más fuerza que en el caso del IFAI, donde el presidente es electo por el cuerpo colegiado, como en nuestra Suprema Corte. Por el otro lado, en la medida que el presidente de la Cofeco tiene claramente todas las responsabilidades administrativas, su poder es muy distinto al del Presidente del IFE, también electo como tal al momento de su elección, por parte de la Cámara de Diputados, pero cuyas responsabilidades administrativas son menos claras y donde el regulado (los partidos políticos) tienen presencia en el Consejo General con voz, aunque sin voto, y donde son estos mismos partidos a través de sus diputados los que eligieron al presidente y a los otros miembros del Consejo General.

El esfuerzo de ver cómo las reglas afectan la operación de otros órganos colegiados será tarea para otro trabajo. Sin embargo, cómo las formas parecen afectar el fondo en nuestro Corte Suprema sugiere que puede ser una línea de investigación fructífera.

\section{BIBLIOGRAFÍA}

Ahumada, Marian, La jurisdicción constitucional en Europa. Bases teóricas y políticas, España, Thomson-Cívitas, 2007.

DAVIS, J. y REYNOLDS, W., "Judicial Cripples: Plurality Opinions in the Supreme Court", Duke Law Journal, vol. 59, 1974.

Dworkin, Ronald, "The Supreme Court Phalanx", The New York Review of Books, vol. 54, núm. 14, 27 de septiembre de 2007.

Elizondo MAYER-SERra, Carlos, "La industria del amparo fiscal", Política y Gobierno, México, vol. XVI, núm. 2, 2009.

- y PÉREZ DE ACHA, Luis Manuel, ¿Un nuevo derecho o el debilitamiento del Estado? Garantía de audiencia previa en la expropiación, México, CIDE, 2009.

FERRERES, Víctor, Justicia constitucional y democracia, Madrid, Centro de Estudios Políticos y Constitucionales, 1997.

GerhardT, M., "The Role of Precedent in Constitutional Decision Making”, George Washington Law Review, vol. 60, 1991.

HALE, Charles, "La tradición del derecho constitucional europeo y el constitucionalismo en el México del siglo XX: el legado de Emilio 
Rabasa", Las Constituciones de la República Mexicana, México, El Colegio de México, 2007.

MacCoun, Robert J., "Voice, Control and Belonging. The Double-Edged Sword of Procedural Fairness", Annual Review of Law and Social Science, vol. 1, 2005.

MAgALONI, Ana Laura, “¿Por qué la Suprema Corte no ha sido un instrumento para la defensa de derechos fundamentales?", en FerrerMacGregor, Edyardi y Zaldivar, Arturo (coords.), Ciencia del derecho procesal constitucional. Estudios en homenaje a Héctor Fix-Zamudio, México, Instituto de Investigaciones Jurídicas, 2008.

e IBARRA, Ana María, "La configuración jurisprudencial de los derechos fundamentales. El caso del derecho constitucional a una defensa adecuada", Cuestiones Constitucionales, México, núm. 19, 2008.

y Elizondo, Carlos, "Cómo decide la Corte", Nexos, septiembre de 2008, vol. XXX, núm. 369.

Magaloni, Beatriz et al., "Activists vs. Legalists: The Mexican Supreme Court and its Ideological Battleships", mimeo.

NovaK, L.,"The Precedential value of Supreme Court Plurality Decisions", Columbia Law Review, vol. 89, 1989, pp. 769 y ss. y M. Thurmon, "When the Court Divides: Reconsidering the Precedential Value in Supreme Court Plurality Decisions", Duke Law Journal, vol. 43, 1992.

ORTIZ MAYAGOITIA, Guillermo, "Apertura del primer periodo de sesiones de 2009". http://www.scjn.gob.mx/SiteCollectionDocuments/PortalSCJN/MediosPub/DiscursosyConferenciasPresidenteSCJN/ENE\%20 02\%202009_GOM\%20APERTURA\%2010\%20PERIODO\%20SESIONES.pdf 14 de diciembre de 2007.

, Informe de labores del Poder Judicial de la Federación 2008, 12 de diciembre de 2008.

"The Statistics", Harvard Law Review, vol. 123, núm. 1, noviembre de 2009.

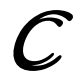

Fecha de recepción: 23 de febrero de 2010.

Fecha de dictamen: 26 de marzo de 2010. 